\title{
Sex, Reasons, Pro Tanto Wronging, and the Structure of Rape Liability
}

\author{
Kate Greasley ${ }^{1,2}$ \\ Published online: 6 March 2020 \\ (c) The Author(s) 2020
}

\begin{abstract}
Some recent scholarship in the philosophy of criminal law has claimed that sexual penetration 'per se'-meaning, consensual or otherwise-is pro tanto morally wrong, or that there exist 'general reasons' against it. On such a view, penetrative sex is only ever at best justified wrongdoing. When paired with an influential view about the theoretical basis of the offence-defence distinction in criminal law, the apparent implication is that sexual penetration alone ought to constitute the actus reus of rape, with the question of consent relegated to a defence matter. This article firstly sets out some of the difficult upshots of considering all sexual penetration to be pro tanto wrong, particularly when one attends to the full moral entailments of justified wrongdoing. Assuming, arguendo, that sexual penetration is pro tanto wrong, it is also far from clear, I suggest, that consent, of all things, amounts to a justification for penetrative sex. This creates further difficulties for the pro tanto wrong view. Finally, I argue that even if penetrative sex is a pro tanto moral wrong of some kind, it does not follow, as some scholars have suggested, that there is a case for making penetrative sex as such (alongside culpability requirements) the offence element of rape.
\end{abstract}

Keywords Rape $\cdot$ Consent $\cdot$ Justified wronging $\cdot$ Pro tanto wrongs · Offences and defences

\footnotetext{
For helpful engagement, I am grateful to participants of the New Directions in Philosophy of Law conference at All Souls, Oxford, in July 2018 - particularly my commentator, Ambrose Lee-and of the Consent Conference held at Cambridge in September 2018. For written comments, I am especially grateful to Karamvir Chadha, Michelle Dempsey, James Edwards, Doug Husak, Patrick Tomlin, and an anonymous reviewer.
}

\section{Kate Greasley}

kate.greasley@ hertford.ox.ac.uk

1 Hertford College, Oxford, UK

2 Faculty of Law, University of Oxford, Oxford, UK 


\section{Pro Tanto Wrongness and Offence and Defence in Rape}

One does not exactly need a reason to avoid a sexual encounter; if anything, the burden of practical reasons has to be discharged in its favour. Assuming an otherwise willing disposition, though, there can be all manner of extant reasons against engaging in sex on any given occasion. Mundanely, perhaps it is a busy day and there isn't the time. Perhaps it is neither the time nor the place. Someone who is the past victim of rape or sexual assault may find sex triggering and distressing. This could be a good reason for that person to abstain from sexual intercourse in general. Perhaps sex will involve a terrible betrayal of another person, or will jeopardise a valuable platonic relationship and isn't worth its cost.

There is nothing particularly interesting or special about these kinds of reasons to avoid sex. They reflect the limitless context-specific reasons we may have against engaging in pretty well any activity. Reasons are ubiquitous. But are there reasons to avoid engaging in sexual intercourse that bear a more special or distinctive character? Do there exist, in other words, general reasons not to have sex, reasons that are always germane no matter when or where or with whom? General reasons of this order would never need to be decisive against sex in order to exist; it is enough that they would present something to overcome, always operative.

Some recent scholarship has taken up interest in the question whether there are general reasons against performing acts of specifically penetrative sex. Why would legal theorists concern themselves with such an ostensibly odd question? A part of the answer could be what that question suggests about the proper positioning of consent in rape liability. The pertinent issue there is whether the victim's lack of consent ought to be a constitutive element of the offence of rape or whether a finding of consent should instead operate as a justificatory defence. In the latter case, the matter of consent is left out of the basic offence requirements. As Peter Westen states the question at hand: is rape the offence of 'sexual intercourse with a person' (with consent available as a justificatory defence) or the offence of 'sexual intercourse with a person without his or her consent'? ${ }^{1}$

The prevailing orthodoxy, in both legal practice and theory, places the victim's lack of consent firmly in the offence-subset of rape. That orthodoxy, in its turn, has been explained by reference to a particular view about what the conceptual distinction between offences and defences consists in. In an influential article, Kenneth Campbell argued that the offence-subset of a crime ought to capture conduct that is 'prima facie' wrong, or that we have reason to avoid in 'all instances'. ${ }^{2}$ Unlike the usual sense of 'prima facie', the term was not meant, in Campbell's usage, to refer to a superficially wrong action whose wrongness turns out, on closer inspection, to be illusory. The meaning is closer to what philosophers sometimes term 'pro tanto' wrongness. Conduct under this description is defined by the fact that its wrong-making features continue to bite in circumstances where the action is

\footnotetext{
1 Peter Westen, “Offences and Defences Again”, Oxford Journal of Legal Studies 28 (2008): pp. 563$584,571$.

${ }^{2}$ Kenneth Campbell, "Offence and Defence", in IH Dennis (ed), Criminal Law and Justice: Essays from the W.G. Hart Workshop (London: Sweet \& Maxwell, 1987), p. 81.
} 
all-things-considered justified (and hence not, on balance, wrong). ${ }^{3}$ John Gardner has elaborated the category in terms of conduct we have continuing reasons not to engage in, reasons which do not merely disappear when a justification is forthcoming, although they may be 'defeated' by the reasons in favour of performing the action. ${ }^{4}$

To take an example, there are strong reasons against inflicting a serious physical assault on another human being, even if so doing is justified in the furtherance of necessary and proportionate self-defence. When a person pleads self-defence in such circumstances, she is claiming that the reasons against her action were outweighed (or 'defeated') by the reasons in favour. But the reasons against the assault have not evaporated either. They very much still exert force, even if they are ultimately overcome by the reasons in favour of defensive action. Campbell's proposal captures the continuing existence of these reasons by means of what Gardner has termed 'the remainders thesis'. ${ }^{5}$ According to the remainders thesis, justified offending, as opposed to mere non-offending, bears the hallmark that 'its commission, albeit justified, remains regrettable'. ${ }^{6}$ While the action is still all-things-considered justified given how events transpired, it is a better state of affairs had it been avoided altogether-better, in my current example, if the person had not needed to resort to defensive violence in the first place. According to the thesis, this marks out the violent defensive action as pro tanto wrong, offence-apt conduct.

The main thought underlying the orthodox view of rape's offence elements is simply that sexual intercourse as such is not regrettable or to-be-avoided conduct. It is not, as Gardner also put it, 'per se an unwelcome turn of events'. ${ }^{7}$ Gardner acknowledged that people might well disagree about whether there are general reasons to avoid any given activity in an argument about offence and defence elements. The important thing is the litmus test provided by Campbell's theory. Hence, regarding rape, Gardner writes:

Those who think that, in the law of rape, sexual intercourse tout court should be regarded as the real offence and consent as a defence had best be able to identify a general reason not to have sexual intercourse, such that one needs a defeating reason in favour before one should engage in it. ${ }^{8}$

\footnotetext{
${ }^{3}$ The original conflation of the terms 'prima facie' and 'pro tanto' has been attributed to the philosopher W.D. Ross: cf Gardner (n4 below) p. 78, and Shelly Kagan, The Limits of Morality, (Oxford: Clarendon Press, 1989) p. 17. Kagan describes the difference between the two terms in the following way: '[A] prima facie principle specifies a moral duty at first glance whereas a pro tanto principle specifies a moral duty sans phrase, unless it is overridden by other moral duties.' Because it is pro tanto wrongdoing with which those making the controversial claim about sexual penetration are clearly concerned, I will continue to use this term throughout, except where quoting.

${ }^{4}$ John Gardner, "Fletcher on Offences and Defences' in Offences and Defences: Selected Essays in the Philosophy of Criminal Law (Oxford: OUP, 2007): 141-153, p. 145.

${ }^{5}$ Gardner, "Fletcher", p. 145.

${ }^{6}$ Id.

${ }^{7}$ Id. at 144

${ }^{8} I d$. at 145 .
} 
Recently, some scholars have taken up Gardner's challenge, attempting to demonstrate that there are indeed general reasons against sexual intercourse as such of the kind that feature in the conceptual distinction between offences and defences. Most prominently, Michelle Dempsey and Jonathan Herring have argued that all sexual penetration is pro tanto wrongdoing that stands in inherent need of justification. ${ }^{9}$ Dempsey and Herring ground this wrongness in certain general features of sexual penetration, meaning, note, consensual or otherwise. These putative wrong-making features include the non-trivial risk of physical harm that can accompany penetrative sex (sexually transmitted disease, unwanted pregnancy, and abrasions or bruising, etc.); the fact that sexual penetration involves the 'literal' application of physical force, and the negative social meaning that heterosexual sexual penetration unavoidably communicates, they argue, given that it is situated in a patriarchal context. This social meaning consists, they say, in the 'the devaluation of women qua women and a disrespecting of women's humanity', with which heterosexual sexual penetration is unfortunately always associated in a society bathed in rape culture and sexism. ${ }^{10}$ The negative connotations of heterosexual penetrative sex in our culture also means, they argue, that even consensual sex 'poses the risk of psychological harm to women', in addition to the more acute risks of triggering past sexual trauma.

For Dempsey and Herring, each of these typical features of sexual penetration is individually sufficient to establish pro tanto wrongness. They acknowledge that there may be many instances of sexual intercourse where the risks of harm are trivial or completely precluded, or where it may not even seem correct to characterise penetrative sex as the 'application of force' by a penetrator. ${ }^{11}$ Nevertheless, they argue, the negative, sexist, connotations of penetrative sex are always present in the prevailing social climate, and are enough to ensure that every single such interaction is pro tanto wrong and in need of justification.

In support of Dempsey and Herring's main thesis, Jesse Wall has sought to shore up the unconventional claim that there are 'general reasons not to have sex'. ${ }^{12}$ By his lights, these reasons stem solely from the fact that all sexual penetration constitutes an 'application of force' ('sufficient to penetrate muscled walls') ${ }^{13}$ which infringes a self-ownership right of the penetrated person. This rights infringement follows from the fact that all penetrative sex involves the 'use and control' of one person by another. 'Simply put', Wall writes, 'penetration of the vagina or anus, forceful or otherwise, is the use and control by the other, rather than the use and control by the

\footnotetext{
9 M Madden Dempsey and J Herring, "Why Sexual Penetration Requires Justification" Oxford Journal of Legal Studies 27(3) (2007): pp. 467-491. The scholarly ancestry of this alternative view traces to George Fletcher, who argued, in his Rethinking Criminal Law, that all sexual touching, including that which is consensual, is such that it requires a good reason to perform. Sexual contact itself, he suggested, fulfils the incriminating offence requirements of sexual crime, and is different in this respect from 'mere touching' not of sexual nature, which does not likewise cry out for justification. See: George P. Fletcher, Rethinking Criminal Law (Boston and Toronto: Little Brown, 1978), p. 707.

10 Dempsey and Herring, "Sexual Penetration", p. 485.

11 Cf their concessions on pp. 474, 477, 478, and 481.

12 Jesse Wall, "Sexual Offences and General Reasons not to Have Sex", Oxford Journal of Legal Studies 35 (2015): pp. 777-798.

13 Id. at 792 .
} 
self'. ${ }^{14}$ This interference with the self-ownership interest of the physically 'invaded' party explains why there are 'general (but defeasible) reasons not to apply penetrative force to another person'. ${ }^{15}$ This is the general feature of sexual penetration that Wall believes calls for justification.

Like Dempsey and Herring, Wall underscores the mere pro tanto wrongness of sexual penetration; all-things-considered justification is still, on both accounts, another matter. Similarly to physical assault, sex could be a justified wrong. This immediately raises the question as to what would constitute such a justification once the pro tanto wrongness of sexual penetration is granted. While Dempsey and Herring prescind from identifying those justifications with any exactitude, Wall's analysis points squarely to consent. For Wall, consent to the sexual activity furnishes the conditions capable of turning the pro tanto wrong of penetrative sex into an allthings-considered justified activity, just as reasonable self-defence can do for the pro tanto wrong of causing grievous bodily harm. ${ }^{16}$

If these scholars are correct that sexual penetration is pro tanto morally wrong, or subject to general reasons of avoidance, what would this entail about the proper offence-subset of rape? Dempsey and Herring explicitly state that they do not mean to draw conclusions about criminalisation, but only to "map the moral landscape of sexual penetration'. Criminalisation, as they note, always invokes a plethora of considerations. ${ }^{17}$ Pro tanto moral wrongs presumably abound, and not even allthings-considered moral wrongs are automatically apt targets for the criminal law. The offence-defence issue is not simply a matter of what conduct to criminalise, though, but of how to carve up all the settled elements of criminal activity. In a the discussion about the offence-subset of rape, the question is not whether all sexual intercourse, consensual or otherwise, ought to be criminalised. As far as I can see, none of the discussants has advocated such a position. The salient question is, instead, whether the presence or absence of consent properly belongs to the offence or defence subset, and on what basis such a choice is to be made.

As with the criminalisation issue, Dempsey and Herring do not commit themselves to any particular basis for assigning elements of a crime to the offence or defence side. Nor do they pronounce on the correct offence-subset of rape. If their thesis, or Wall's thesis, as regards sexual penetration is correct, however, then it appears (certainly at first blush) that "sexual penetration as such" meets the Campbell-Gardner test for picking out the offence elements of a crime. If sexual penetration is pro tanto morally wrong, and subject to general reasons of avoidance, then it follows, or so I shall suggest, that it is indeed 'per se an unwelcome turn of events' and generates continuing reasons of avoidance which survive through justification, crystallising into moral remainders in the event that a justification does obtain.

\footnotetext{
${ }^{14} I d$.

15 Id.

16 He writes: ‘. . .although there are general (and defeasible) reasons not to engage in penetrative sex (and hence penetrative sex can be described as a prima facie wrong), the provision of consent is able to justify an act of penetrative sex...' (Wall, “General Reasons”, p. 795).

17 Dempsey and Herring, "Sexual Penetration”, pp. 467;471.
} 
For those that are minded to accept the Campbell-Gardner view of offences and defences, then, the 'pro tanto' wrong view of sexual penetration yields at least a prima facie case for designating the offence-subset of rape as 'sexual penetration as such', with consent relegated to a defence issue. In fact (and as we shall see more of presently), it is really on the basis of Campbell's conceptual distinction that Wall explicitly challenges the inclusion of lack of consent in the offence-subset of rape. 'The implication [of general reasons against sex]', he writes, 'is that for such crimes the provision of consent ought to be available as a justificatory defence rather than the absence of consent being an element of the offence. ${ }^{18}$ In short, Wall thinks, because there are general reasons to avoid sexual penetration as such in 'all instances', it can be fittingly picked out as the offence-subset of rape-without reference to consent-as per Campbell's test.

In what follows here, I firstly throw doubt on the thesis that penetrative sex is only ever, at best, a pro tanto yet justified wrong, primarily by considering the normative implications the truth of this would have for sexual relations under any conditions. Assuming the pro tanto wrong thesis arguendo, I also adduce problems with supposing that consent of all things could stand in as a general justification for sex, including — maybe particularly_before the law. These reflections are meant to call into question the kernel of the pro tanto wrong thesis. Focusing more specifically on Wall's account, I argue that it is, in any case, not enough to show that sexual penetration per se is the presumptive offence of rape merely if one can adduce any generally applicable reasons against penetrative sex, or demonstrate that it is a pro tanto moral wrong of some kind. This argument, I believe, moves from a misapplication of the framework for distinguishing offence from defence elements from which it proceeds.

One necessary aside: it goes without saying that the very existence of a conceptual distinction which "yields a neat contrast between offences and defences ${ }^{19}$ is contested in its own right. Sceptically, one might ask: if consent precludes criminal liability for rape one way or the other, what difference does it make whether this is catered for through what is strictly speaking the offence or defence elements? The bigger question for criminal law theorists is whether that difference ever matters in a way that transcends procedural expediency or the apportioning of evidential burdens. That is not a question I will attempt to answer here, although I am minded to agree with Gardner that that not all moral and legal significance in offences and defences depends on making a 'constitutive difference' to condemnation, punishment, deterrence, and so on. ${ }^{20}$ Since the advocates of the 'pro tanto wrong' thesis do not contest that conceptual distinction (in Wall's case, it is even relied upon to challenge the orthodox position on offence and defence in rape), I will grant it in the present discussion.

\footnotetext{
18 Wall, "General Reasons", p. 1.

19 Gardner, "Fletcher", p. 141.

20 John Gardner, "In Defence of Defences", in Offences and Defences: Selected Essays in the Philosophy of Criminal Law (Oxford, OUP, 2007), 77-89, p. 80.
} 


\section{Justified Wrongdoing and the Remainders Thesis}

Let us recall the remainders thesis, which Gardner considered the hallmark of pro tanto wrongdoing. At a glance, the remainders thesis is a bad fit with sexual penetration per se. For it holds, we saw, that pro tanto wrongs are 'unwelcome turns of events' even when they are justified. For most people, this does not ring true of welcome, consensual sex. This kind of sex, it is assumed, is not ideally to be avoided, as committing a violent assault is. Since 'sexual penetration as such' includes consensual sex, it is thus an awkward candidate for moral remainders. Contrariwise, the remainders thesis is a comfortable fit with non-consensual sex, considered in isolation. Even in an outlandish scenario where it is just about conceivable that a rape were justified (to avert nuclear holocaust, say ${ }^{21}$ ), it would nonetheless be highly regrettable and the fitting object of serious grief and sorrow.

Dempsey and Herring argue that a 'moral residue of regret' does in fact attend, or ought to attend, all acts of sexual penetration, consensual or otherwise. ${ }^{22}$ In this respect, they liken sexual penetration to surgery, which they also characterise as at best a justified wrong. While surgical cutting is justifiable through its necessity, it 'is still to be regretted', they say. The aptness of that regret is demonstrated by the fact that less invasive methods of treatment or diagnosis should always be preferred where possible. ${ }^{23}$ This obligation to seek these 'less wrongful alternatives' is symptomatic of 'the rational force of regret' that always accompanies justified wrongs. ${ }^{24}$ Both such activities, in their view, thus conform to the remainders thesis. ${ }^{25}$ Because of the unfortunate features that accompany sexual penetration (usually the 'application of force'; always the dehumanising symbolism), the 'moral residue of regret' taints every act of sex, as it does surgery, notwithstanding all-things-considered justification.

The analogy with surgery is somewhat strained, however. While it is intelligible to regret at the very least that things were such that invasive surgery was rendered necessary, this would be an odd attitude to take toward sex that is consensual and welcome. So the remainders thesis does not apply with equal ease to all sex. Surgery certainly is ideally to be avoided, but few will accept that this is true of consensual sex. It is also interesting to ask what the obligation to seek out 'less wrongful alternatives' would entail in the case of sexual penetration. With regard to surgery, it is clear enough what alternatives medical staff are obligated to exhaust. As Dempsey and Herring point out, if the purpose of surgery were, say, to explore the source of a patient's abdominal pain, then it is 'rationally incumbent' on medical staff to first

\footnotetext{
21 I do not mean in saying this to commit myself to the view that there are conceivable circumstances in which such a thing could be justified. Depending on one's moral outlook, rape, like torture (and, indeed, as a form of torture) might be impermissible no matter what catastrophe it outlandishly would avert. I leave this open here. The point is only that, were any such justification to obtain, moral remainders would undoubtedly loom extremely large.

22 Dempsey and Herring, "Sexual Penetration", p. 488.

${ }^{23} \mathrm{Id}$.

${ }^{24}$ Id. at 488-489.

25 Id. at 482.
} 
seek less invasive alternatives for diagnosis, such as X-rays, blood tests and so on. ${ }^{26}$ But this duty to seek out 'less wrongful alternatives' may throw into doubt the moral permissibility of consensual sex in general.

More light might be shed on this question when we reflect on the full moral attendants of pro tanto wrongdoing. As Dempsey and Herring are clearly aware, the most obvious implication of pro tanto, justified wrongdoing is that in the best-case scenario it is avoided. Thus, in the self-defence example, the remainders thesis suggests that if I could choose between defeating my attacker in an act of justified selfdefence and not being attacked in the first place I should choose the latter, and avoid committing the pro tanto wrong that I know would be justified in the circumstances. I am justified in using aggressive defensive force if attacked in an alleyway, but I certainly shouldn't go looking for trouble. ${ }^{27}$

Let us suppose, then, that I am walking home late on a freezing cold night and could spare myself 5 min of extra walking time by taking a short cut through a certain alleyway. The alley is a well-known site of night- time attacks. Let's suppose further that instead of being as fantastically feeble as I am, I am in fact implausibly strong and a formidable prospect for any would-be assailant. I am confident that, if attacked, I will be able to dispense some vicious and effective justified defensive force and easily immobilize him. It would still be better overall were I able to avoid altogether being so placed that I am forced to resort to justified defensive force, and, depending on the circumstances, I may even be morally required to do so. If obligations of this type exist, they will be shaped, presumably, by the onerousness of avoidance. Perhaps I am not put upon to avoid the altercation at the cost of an extra twenty minutes of a freezing walk. Contrast this with a different walk on a different night, though, and still supposing my implausible strength. This time, the alley is no short cut, but I have been crossed one or two too many times that day, and there is nothing I'd relish more than the opportunity to justifiably beat up an attacker. In such a scenario, I think I could be rightly admonished for choosing the course of action that will likely lead to my committing a justified wrong so as to sate my appetite for violence. Likewise, it would appear, if I am not out for blood, but still know that I could avoid both an attack and my justified defence by going only two minutes out of my way.

As these vignettes bring out, the fact that a justified wrong is on the horizon can alter our moral duties upstream of the wrong. Specifically, it can import something in the way of a duty of reasonable avoidance. A number of considerations might be thought germane to that duty, including just how avoidable the justified wrong is, but also whether it is worth its cost, and, surely, how serious a pro tanto wrong we are talking about. Let us amend my night-walk scenario once more to hold that this time, although I'm confident in my ability to defend myself, I have only one powerful ninja move in my defensive arsenal, and it is certain to kill the assailant. We can assume that, once confronted by an attacker, the threat to my physical integrity

\footnotetext{
${ }^{26}$ Id. at $488-489$.

27 I am indebted to Dori Kimel for first bringing the issue of moral obligations to avoid justified wrongdoing to my attention, with the use of examples similar in their structure to those I employ here.
} 
would be serious enough to justify my fatal move, if it's the only play I have. Still, given that the justified wrong on the horizon is now killing, my duty to avoid the entire scenario is surely far stronger. Perhaps I am now permitted to take the short cut only if it is the sole means of getting home at all, rather than spending the freezing night on the streets.

As seen, Dempsey and Herring do appear to acknowledge something in the way of a duty of reasonable avoidance when specifying the duty to explore 'less wrongful alternatives'. But what does this duty amount to, once one considers that consensual sex is eminently avoidable? To be sure, sexual abstinence may be costly, for most people at any rate. The alternatives are not as good, just as blood tests and $\mathrm{x}$-rays might not be as conclusive a diagnostic tool as surgery. But this is precisely where we should expect to see the ripple effects of pro tanto wronging showing up the most starkly: where inferior but 'less wrongful' alternatives present themselves. It is worse for me to take the long road home than to take the short cut and flatten an assailant in my path. But it will still get me home, and not at the cost of committing a serious, if justified, wrong.

If penetrative sex is a pro tanto wrong of any magnitude, it is hard to avoid the implication that in the most ideal circumstances, no such activity would happen at all, and that the duty of reasonable avoidance looms large. The intuitive upshot is that people should strive toward celibacy, the way that many people strive to cut their carbon emissions or reduce their meat consumption (I am reminded here of the apostle Paul's exhortation to the church of the Corinthians to be single if they can but marry if they must, since it is better to be married than to "burn with passion". ${ }^{28}$ ) The question we should all be asking is when such activity cannot be reasonably avoided. Needless to say, this would be a fairly revolutionary ethics of sex.

Perhaps it will be suggested that these fairly drastic entailments can be avoided if the nature of the moral remainder is only suitably finessed. The sense of 'regrettable' involved in justified wronging need not introduce any psychological state of regret, it might be said, but refers only to the existence of some residual disvalue. ${ }^{29}$ As with necessary surgery, the remainder or 'moral residue of regret' might amount to nothing more than the sensible thought that it would be better if the good things secured by sexual intercourse could be achieved without the negative hitchhikers; it is not the psychological disposition to all-in regret acts of welcome sex. ${ }^{30}$ Relatedly, it might be objected that I have overstated the normative implications of pro tanto wrongdoing with the duty of reasonable avoidance. Toward the end of their discussion, Dempsey and Herring reflect that the pro tanto wrong status of sexual penetration could amount to nothing more than 'a reason to acknowledge and reject [its]

\footnotetext{
281 Corinthians 7:9.

29 I am grateful to Doug Husak for suggesting this possibility to me.

${ }^{30}$ I set aside here the further worry that it may lack intelligibility to imagine how the distinctive values of sexual intercourse could be secured outside of that sexual activity. Is it cogent to wish that the unique pleasure of an ice cream on a hot day could be managed without the ice cream and the hot day? The parsing manoeuvre is effective enough when the aim of reproduction is singled out: we can well imagine-and do not need to imagine-creating babies without sexual intercourse. When it comes to the nonprocreative values, though, the thought is more challenging.
} 
negative social meaning' - in other words, a duty to mitigate the pro tanto wrongmaking features, rather than to reject penetrative sexual activity wherever possible. ${ }^{31}$

These modifications would certainly take the sting out of the remainders thesis, vis-à-vis welcome sex. The problem is that glossing the remainders thesis this way threatens to dilute the notion of pro tanto wrongdoing to something so capacious as to lose its meaning. As I noted at the beginning, simple reasons not to do something abound. There are almost always reasons not to do things, which may manifest in residual negative value; very few things are just good. For example, as I squint at the computer screen to write this paper, my eyesight is deteriorating. It would certainly be better if I could read and write without this unwelcome side effect. In other words, what we might call 'rational remainders' are everywhere: reasons against an activity which might be defeated, but are not extinguished, by the reasons in favour. But if pro tanto moral wrongdoing is to have meaning at all, the kind of remainders that distinguish it must capture something more piquant than this. It is otherwise hard to see how pro tanto moral wrongdoing picks out a distinctive category of conduct at all, since rational remainders are so ubiquitous.

Contrariwise, the designation 'pro tanto wrongdoing' does pick out a distinctive normative category of conduct if it is in the nature of that conduct that, even when justified, it is the fitting object of a certain degree of regret, directed at a non-trivial moral wrong the agent committed. I struggle to see that we can separate the normative implications of at least reasonable avoidance from conduct that carries serious moral remainders and keep the subject matter fixed. This is borne out in the correct attitude to clear examples of justified wrongs, such as defensive violence, which imports an obvious duty to 'seek out less wrongful alternatives', in Dempsey and Herring's own language. This duty - putting it otherwise, a duty to avoid when possible-is simply the reverse side of the need for justification. ${ }^{32}$ Finally, if the participants in sexual activity were able to preclude or counteract its pro tanto wrong-making features, by, say, rejecting its negative social meaning, as Dempsey and Herring propose, this would undermine the initial claim that all sexual penetration 'as such' is pro tanto wrong: instances of sex where those wrong-making features are missing would not be.

While Dempsey and Herring do not focus on the apt moral responses to their claim about the nature of sexual penetration, its normative implications bear on its plausibility. The duty of reasonable avoidance ups the stakes of what it means to accept that claim.

\footnotetext{
31 Dempsey and Herring, "Sexual Penetration", pp. 490-91.

${ }^{32}$ It is far from clear to me that even the collateral damage of surgery is properly described as a moral remainder rather than a rational one. Of course, there are reasons to avoid surgery if one can do without it. But surgeons do not have cause to feel any sense of real sorrow at what has come to pass when a successful surgery is completed; they have not found themselves in a situation where they must commit a non-trivial moral wrong in order to do the right thing, or so I'm inclined to think. I will return to this briefly towards the end.
} 


\section{No Moral Remainders?}

The remainders thesis is a significant impediment to the claim that sexual penetration per se is pro tanto morally wrong, since we do not think, or certainly act as if, consensual sex is subject to moral remainders, and sexual penetration 'per se' includes consensual sex. But perhaps I am still wrong to suppose that all justified, pro tanto wrongs carry moral remainders. Jesse Wall has argued that we can accept there are general, defeasible reasons not to have sex, while at the same disavowing the counter-intuitive notion that consensual sex leaves moral remainders. On his account, the general reasons against penetrative sex stem solely from the literal 'application of force' required for sexual penetration which, he argues, infringes the 'invaded' person's right to exclusive control of one's body, akin to a right of selfownership. As seen, sexual penetration as such involves, he alleges, the 'use and control by the other', and as such, is in inherent need of justification. ${ }^{33}$ This justification always obtains in conditions of consent, Wall claims. However, when consent justifies the pro tanto wrongful act of penetration, it does so in a way that, he argues, leaves behind no moral remainders.

Wall's path to this conclusion travels through his particular account of sexual penetration's pro tanto wrongness. The general reasons against sex, as he sees, it, stem from the infringement of a self-ownership right which attaches to acts of sexual penetration, via the literal application of force. But in conditions of consent, one exercises one's self-ownership in favour of sexual activity. ${ }^{34}$ The way consent works to justify sex, then, differs from the way consent standardly works to permit otherwise impermissible activity. On the standard picture, he notes, consent does not cancel out the reasons against performing an action, but only permits one to act in spite of them (e.g. the harm the surgery may cause to me has not been made to disappear through the exercise of consent; it only allows the surgeon to press on regardless of those reasons). In sex, though, consent does not outweigh but extinguishes the selfownership based general reasons against the action. ${ }^{35}$ The 'transformative' effect of consent means that there is nothing left to be regretted about consensual sex, then, just as, he says, 'surgeons...do not have a long list of regrets following a day full of surgical procedures, the rugby field is not covered with residual regret following a match full of forceful tackles' ${ }^{36}$ In these other examples, which also involve 'applications of force', the self-ownership based 'general' reasons not to engage in the activity are evaporated through the giving of consent.

Wall's approach is a clear attempt to avoid the embarrassment of the remainders thesis for consensual sex, whilst keeping the basic claim about general reasons to abstain from penetrative sex as such. Yet if the general reason against sexual penetration is completely extinguished in conditions of consent, then the obvious reply is that this general reason simply will not apply in the first place to consensual

\footnotetext{
33 Wall, "General Reasons", p. 792.

34 Id. at $797-798$.

35 Id. at 796.

36 Id. at 798.
} 
sex. There will not be, therefore, a general reason against penetrative sex in 'all instances' - certainly not in the sense of there being reasons against it that survive justification, which Gardner and Campbell seemed to identify as the nub of pro tanto wrongdoing. Wall's picture of justified sexual penetration is nothing like justified defensive violence, for instance, where the reasons against harming an assailant never cease exerting their force. Consensual penetrative sex is conduct which, by Wall's own lights, does not stand in need of justification. While Wall speaks of consent as resolving the 'conflict of reasons' for and against sex, his analysis entails, rather, that no such conflict exists to begin with in respect of sex that is consented to.

It seems that for Wall, what is involved in there being general reasons against consensual sex is no more than that there are reasons for doing otherwise that would have applied were the circumstances different. Well, aren't there always? It is a reason not to accelerate down a road if I might plough into a pedestrian crossing the street. I'm in the middle of nowhere and there is no pedestrian for miles. Is there a 'general reason' against accelerating down the road? If the putative general reasons against sexual penetration can be disappeared by dint of consent alone, we are ostensibly barred from holding that they apply as a matter of generality. Since Wall claims that there is a transformative moral difference between consensual and nonconsensual sex, we are still owed an explanation for why this difference does not go to the issue of pro tanto wrongness itself, rather than only to all-things-considered wrongness. Precisely given that Wall wishes to persuade us of general reasons against having sex in "all instances", it is surprising that he identifies those general reasons with a feature that only holds in respect of one category of penetrative sex, namely, the non-consensual kind. ${ }^{37}$

\section{Justifying Through Consent}

Wall's account effectively claims that the pro tanto wrong of sexual penetration can be justified, or rather neutralised, by consent. This, as seen, is because he believes that consent cancels or extinguishes the general (in his view, self-ownership based) reason against having sex. On the standard account of justified wrongdoing, however, the reasons against performing the wrong continue to bite even where it is

\footnotetext{
37 By way of contrast, Dempsey and Herring's grounds for ascribing pro tanto wrongness to all acts of sexual penetration do cite features of sex that apply regardless of consent: the application of physical 'force' simpliciter, risks of physical and/or psychological harm, and the 'negative social meaning' of women's objectification and dehumanisation. Yet only this last feature, as we saw, do they believe holds necessarily in respect of all acts of sexual penetration. As Wall points out, even this putative feature of sexual penetration only holds contingently: sex does not carry this negative social meaning (if indeed it does) in all possible worlds (Wall, "General Reasons", p. 785). I think Wall is wrong to object, as he does, that features of acts which hold only contingently and not in all possible worlds cannot give rise to general reasons against performing a given act-type. Nevertheless, while Dempsey and Herring's analysis does, unlike Wall's, identify general negative features of penetrative sex which survive justification, they expose themselves to the main objection from the last section: that this has highly counter-intuitive implications for our attitudes to consensual sex.
} 
justified. Any consent-based justification would not cancel out those general reasons against sex; it would need to overcome them. But would it, necessarily?

There are great difficulties with thinking that consent, of all things, is capable of defeating strong moral reasons against sexual penetration, should those reasons exist. Consider the oddness of this exchange: "Q: Why did you have sex with him? A: Because he consented!" As Wall rightly acknowledges, the act of consent is only permissive or empowering. Consent is a 'cancelling permission', not a defeating reason, in that it does not provide the reasons in favour of performing an action; it only releases one to act on certain reasons in favour of that action, sometimes in spite of the extant reasons against it. 'J8 'Just because a person consents to penetrative sex', Wall writes, 'does not mean that there is a reason to engage in penetrative sex with that person.' ${ }^{39}$ That is quite right, and it underscores a more general point about the relevance of consent for justified wrongdoing. Consent itself is not what provides the justificatory grist when it empowers one to do what would otherwise be wrong. This is sharply brought out by the myriad circumstances in which consent abjectly fails to justify harmful conduct. The power of my consent cannot justify someone in lopping off my arm for fun. If severing my limb is the only way to save my life, on the other hand, (perhaps it has become gangrenous), the action will be justified, subject to my consent.

Notably, under English law, consent is not a valid defence to inflicting anything more than very minor harm unless that harm is inflicted or risked for a good reason, deemed capable of offsetting its negative value. Thus, medical interventions, bodily decorations, rough or dangerous sports and the like have traditionally existed as exceptions to the general prohibitive rule against inflicting anything beyond minor bodily damage, on the footing that the public utility of the exercises outweighs the harm done or risked through them. ${ }^{40}$ In all these cases, consent is indeed 'transformative', to use Wall's word, in that its provision makes the difference between an assault and 'a praiseworthy athletic act' such as a rugby game, or permissible surgery. However, the "defeating reasons", as it were, come from the public valuing and enjoyment of contact sports, the goods of athleticism, and the necessity and curative potential of medical interventions. It is only because the law deems it that these values sufficiently outweigh the harms caused or risked that consent is allowed to be permissive or empowering in these contexts. I am not justified (morally, or under the law) in savagely beating up my neighbour for fun, consent or no. ${ }^{41}$

\footnotetext{
38 This account of the way consent operates to change the normative status of actions has also been put in terms of consent 'unexcluding' certain reasons in favour of performing an action which would, absent consent, remain excluded, is in turn attributable to John Gardner (cf "Justifications and Reasons" in Offences and Defences, 91-120 and "Fletcher", p. 148 (speaking of not consent specifically, but justifications tout court), and Joseph Raz, Practical Reasons and Norms (Hutchinson, 1975), pp. 96-97.

39 Wall, "General Reasons", p. 796. Emphasis his.

40 See $R v$ Brown [1993] 2 All ER 75.

41 In some cases, we may be unsure about whether the value of a lawful activity truly compensates for the amount of harm inflicted by it, as some people feel about boxing. But notice that the abolitionist view of boxing has nothing whatsoever to do with consent, which is presumptively always forthcoming.
} 
On the assumption that sexual penetration as such is in need of justification, then, it is the value of sexual intercourse, when it is valuable, that would need to supply the real justificatory force. As in these other contexts, consent does not, in and of itself, provide that value. Indeed, Dempsey and Herring acknowledge that the value of legitimate sexual relations comes not from consent but from other things. ${ }^{42}$ As they say elsewhere: 'the value of sexual penetration (i.e. the positive aspects of sexual penetration) can be found in a wide variety of things...in the circumstances surrounding the act, the meaning the parties attach to it, and the consequences of it' ${ }^{43}$

This statement does seem to grasp at the sorts of values one would have to invoke to overcome general reasons against sexual penetration, should they exist. Although they are not supplied by consent, they of course presuppose it. To have any positive value, sexual interactions must be to start with consensual. Yet they may be consensual whilst at the same time wholly lacking in value. All manner of cynical or sordid sexual interactions can manage to reach the low moral bar of consent. Indeed, it has been a key theme of both feminist and other philosophical contributions to this topic that we should not expect so much of consent when it comes to distinguishing good from bad sexual interactions. ${ }^{44}$ Consensual sex can be not only devoid of value, but also echo much of the pernicious objectification inherent to rape itself. Gardner has summarised this idea in recent work as 'the thought that consent is insufficient to vindicate sex, to guarantee its good quality or even its moral acceptability. ${ }^{45}$ Expecting consent to make all the difference between worthwhile and valueless — or even morally fraught—-sex, was always to expect more from that power than it is capable of doing.

Because mere consent does not ensure good or valuable sexual interactions, it would be as improper to look to justify penetrative sex by reference to consent as it would be to justify surgery or boxing by pointing out that no one is forced into it. Granted, but that hardly gets us very far. Since it is clear that consent does not supply the values of sex (although it is a necessary condition for them), the revisionist view carries the burden of explaining how sexual penetration gets to be generally justified in conditions of consent. If this is the role consent is given to play in the structure of rape liability on Wall's outlook, it is patently not up to the task.

In the realm of sexual intercourse, the connectedness of consent with the value of the activity can make it easy to conflate the two, since they are bound up together

\footnotetext{
42 Dempsey and Herring, "Sexual Penetration", p. 491.

43 Jonathan Herring and Michelle Madden Dempsey, "Rethinking the Criminal Law's Response to Sexual Penetration" in C McGlynn and VE Munro (eds), Rethinking Rape Law: International and Comparative Perspectives (Taylor and Francis 2010) pp. 30, 38-40, 37.

44 See, particularly: Stephen Shute and John Gardner, 'The Wrongness of Rape' in J Gardner (ed), Offences and Defences: Selected Essays in the Philosophy of Criminal Law (OUP 2007): pp. 1-32; John Gardner, "The Opposite of Rape", Oxford Journal of Legal Studies, 38(1), (2018): pp. 48-70, Robin L. West, "Sex, Law, and Consent", in Franklin G. Miller \& Alan Wertheimer eds. The Ethics of Consent: Theory and Practice, (New York: Oxford University Press 2010), pp. 221-250 and "Legitimating the Illegitimate: A Comment on "Beyond Rape", Columbia Law Review 93 (1993): 1442-1459; and Catharine A. MacKinnon, "Rape: On Coercion and Consent", in Toward a Feminist Theory of the State, (Cambridge, Mass. HUP, 1989): 171-184.

45 J. Gardner, "The Opposite of Rape", p. 60.
} 
in a way that is not true of, say, surgery or rough sports. It is hard to imagine sex embodying any of its values while falling short of being consensual, whereas we could imagine a form of coerced gladiatorial-style combat that still secures the values of athletic prowess and public enjoyment typically sought out by boxing; or forcible surgery, which nevertheless cures the patient of a terrible ailment. We should not let this throw us off, though. As with the comparison activities, the provision of consent alone does not guarantee that the necessary overriding values are present in a sexual encounter, if sexual penetration were pro tanto morally wrong.

On Wall's account of justified sex this is not a problem, since consent does not need to defeat the reasons against sex; it makes those reasons disappear. It need not correlate to any further positive values for that. But as we saw in the previous section, Wall's account did not furnish us with general reasons against sexual penetration as such, since the basis for pro tanto wrongness he picks out (the violation of a self-ownership right) does not apply to consensual sex.

\section{Bad Sex and the Presumptive Wrong of Rape}

The ubiquity of consensual yet valueless-even morally problematic-sex is an ostensible issue with the pro tanto wrong thesis for anyone who thinks that sex is allthings-considered justified in conditions of consent. It throws doubt on the robustness of consent as a general justificatory defence to sexual penetration. ${ }^{46}$ Despite this, the possible badness of consensual sex has actually been used to fuel the suggestion that sexual penetration per se should constitute the offence-subset of rape. This requires some explanation.

Firstly, recall my criticism of Wall's account in Sect. 3: that the general reason against sex which he identifies does not apply to consensual sex. Only non-consensual sex involves a 'denial of a person's non-use value', and is inconsistent with her rights of self-ownership. Wall in fact anticipates this answer to his argument. Even so, he replies, the inclusion of lack of consent in the offence-subset of rape is revealing of a certain presumption about sex undergirding the orthodox view. This presumption is 'that a person exercises their rights of control over their body in favour of sexual activity'. ${ }^{47}$ Wall thinks that a certain asymmetry between sexual and nonsexual offences helps flush out this presumption. He illustrates thus:

Consider two hotel rooms in L'Hotel de l'information imparfaite. Two people enter Room 1, and after some time, one of the emerges from the room

\footnotetext{
46 One might wonder whether consent could operate instead as an excusatory defence to penetrative sex (as explored by Wall in Jesse Wall, 'Justifying and Excusing Sex", Criminal Law and Philosophy (2019) 13: 283-307). I am dismissing this line of thinking, if only for the reason that the revisionary scholarship at issue here seems clearly to place consensual sex in the category of justified wronging, not excused wronging. One clear problem for the excusatory framework is that it even more forcefully entails consensual sexual conduct, no matter how defensible, ought not to have happened and should be bemoaned. Even more problematically, it holds that the perpetrator is blameworthy for partaking in what is an allthings-considered wrong, though that blame may be somewhat mitigated.

47 Wall, "General Reasons", p. 793.
} 
with bruising around their eye socket. Two people also enter Room 2, and after some time, one of them emerges with vaginal (or anal) bruising. We know very little about the events that occurred in both rooms except that we know that the bruising was caused by the actions of the other person in the room. ${ }^{48}$

Wall points out that the criminal law reacts differently to the events of Room 1 and Room 2. On these facts alone, we know enough about Room 1 to make out the offence of assault occasioning actual bodily harm. The bare facts of Room 2, on the other hand, are insufficient to establish the offence elements of a sexual offence. We need lack of consent for this. Why the asymmetry? Wall's answer, drawing on some ideas of Peter Westen, is that the orthodox view illicitly presumes sexual activity is welcome and valuable (not so a black eye) or, as he puts it elsewhere, that 'a person's body has a default setting in favour of sexual activity'. ${ }^{49}$

Against this presumption, Westen argues that it is not, in truth, easy to make any general statements about the goodness or badness of sexual penetration 'as such', given the multiplicity of contexts, good and bad, in which it occurs. ${ }^{50}$ As we well know, even consensual sex can vary dramatically in terms of its welcomeness and positive value. Perhaps the abstract question 'Is sexual intercourse per se socially desirable?' is not one that can be answered, then. ${ }^{51}$ As Westen notes, that conduct equally describes both a married couple of many years having sex on their anniversary, and a sixteen year-old intoxicated teenager who is taken advantage of by a much older married man with children, deceiving her about his circumstances. Westen charges those who think there is nothing to account for in penetrative sex 'as such' with having only the good contexts, the mutual, loving, or at the least, symmetrically agential, sex, in mind. To be sure, the anniversary couple do not have something to account for, but the exploitative older married man certainly does. ${ }^{52}$ 'What is wrong', Westen concludes, 'is to think that lawful sexual intercourse is socially understood to be either costly or costless in all the circumstances under which it occurs'. 53

Building on these reflections, Wall's charge is that the orthodox structure of rape liability is predicated on a blinkered, or one-sided, view of what penetrative sex is like. When Gardner claims that sexual penetration per se is 'not per se an unwelcome turn of events', he asks, what is the term 'per se' keeping in and out of the equation ? $^{54}$

It is not accidental that Westen's contrasting examples are both within the realm of consensual sex. Of course, rape is also an example of sexual penetration, but Westen does not contrast the ideal anniversary sex case with rape, but instead with a

\footnotetext{
48 Id. at $778-779$.

49 Jesse Wall, 'Justifying and Excusing Sex”, Criminal Law and Philosophy (2019) 13: 283-307, p. 289.

50 Westen, "Offences and Defences Again" at 573.

51 Westen, "Offences and Defences", p. 563.

52 Id. at 573.

53 Id.

54 Wall, “General Reasons", p. 793.
} 
form of exploitative, morally fraught, consensual sex. ${ }^{55}$ This highlights the underlying importance of bad consensual sex in this challenge to the orthodox view. That view can readily acknowledge the moral heterogeneity of sexual penetration, which can range from outright rape to the most mutually engaged of encounters, and everything in between. But it posits a crucial dividing line between the consensual instances and the non-consensual ones for the purposes of delineating the presumptive wrong of rape. The possibility of morally fraught consensual sex puts pressure on this dividing line. Given that much consensual sex is nevertheless exploitative, objectifying, etc., perhaps it is wrong to presume that sexual penetration is welcome, favourable, and non-problematic.

That presumption would indeed be unwarranted. Is that a presumption the orthodox view makes? I think not. Still less does it make the presumption that people's 'default settings' are in favour of sexual activity, or that people are always poised to exercise their bodily rights in favour of sex. Of course, if it is not possible to say anything generally true about sexual penetration per se, given its wavering contexts, we should ask why marking it out as presumptively wrong and inherently in need of justification is not equally as illicit. In fact, the orthodox view of rape liability does not make any presumptions either way about the typical value or welcomeness of sexual activity.

Let us go back to Wall's two rooms. The unwarranted presumption with which Wall charges the orthodox view is potentially ambiguous between two things, and it is useful to separate them: 1 . That view presumes that sexual penetrative contact, where it happens, is consensual, and/or 2. The view presumes that sexual penetrative contact, where it happens, is a valuable, welcome activity. Let us take the first presumption. Does the current legal structure presume consent is forthcoming when sexual activity happens? No such thing follows from the fact that lack of consent is part of the offence-subset of rape. The law of rape does not presume that sex, where it happens, is consensual, but only that sex, where consensual, is not the presumptive wrong of rape. Neither does it make the second possible presumption: the law of rape does not presume that sex, where it happens, is valuable, welcome, and nonexploitative. It stipulates that consensual sex is not a criminal wrong, even presumptively, and, in particular, is not the presumptive wrong of rape.

To explain this further, it is useful to return to a point made near the beginning. We can distinguish two questions about crimes and their offence elements. First, should ' $X$ ' be a crime? And second, Where ' $X$ ' is a crime, which elements of $X$ should be offence and defence elements? ${ }^{56}$ Let us take it that ' $X$ ' here is having non-consensual sexual intercourse with a person, with the appropriate mens rea. As far as I can see, Wall's account does not contest that this is the consummate crime of rape, and that consent therefore is crucial to commission or exoneration. But it is

\footnotetext{
55 Westen clearly means for us to assume here that the teenager is not intoxicated to the point of incapacity, so that the sex still passes the bar of consent. He describes the teenager's intoxicated state as being 'less than sufficient to render her incompetent to have sex'.

56 Thank you to James Edwards for helping me to clarify this.
} 
another thing to have reasons to make particular elements of a crime offence rather than defence elements. This is more a question of what belongs where.

Wall's train of reasoning seems to be that either because sexual intercourse per se admits of general reasons of avoidance-or is pro tanto morally wrong-there is a case for making it alone the offence-subset of rape, inkeeping with the CampbellGardner conception of offences and defences. But this, I believe, would be to misapply that conceptual distinction. Determining the offence-subset of a crime such as rape cannot just be a matter of asking which discrete act-types within the composite crime amount to a pro tanto moral wrong, or contain some residual negative value (and general, defeasible, reasons to avoid something come cheap). The question is rather what is the prohibited conduct for which a person is called to answer under this crime?

We can take, for instance, Campbell's own example of the crime of 'operating a radio receiver without a licence', through which he exposits the offence-defence distinction. ${ }^{57}$ How do we determine whether the absence of a licence should be part of the crime's offence, or whether the offence should rather be that of operating a radio receiver, subject to the defence of owning a licence? As we know, Campbell's answer was to look for the pro tanto (in his parlance, 'prima facie') wrongful conduct. This included the lack of a licence, since there is nothing wrong with operating a radio receiver as such. But let us imagine what the reasoning we encountered above could do with this example. Perhaps operating a radio receiver is not a good or valuable activity in all contexts. Maybe there are even general reasons to avoid operating a radio. A good one could be that there is only ever unedifying trash being broadcast.

Once we know this much, the argument might go, we have established that the offence ought simply to be 'operating a radio receiver', without reference to a licence. Now this would surely be a distortion of Campbell's distinction. For his clear meaning was not that the offence should be identified with any act-type referenced in the crime which one has general reasons to avoid. The offence-subset, on Campbell's account, is better understood, I think, to be the pro tanto wrong conduct which is targeted by the particular crime in focus, and for which a person must be brought to answer under its auspices. In the crime of 'operating a radio receiver without a licence', the bad action for which the agent is called to account is patently not 'operating a radio receiver', whatever one thinks of the goodness, badness, or moral inertness of radios in general.

Engaging in exploitative, dehumanising consensual sex might well be a pro tanto wrong of some magnitude. The exploitative married man from Westen's example has something to answer for all right. Is it the same thing that a person who rapes someone has to answer for? Those who think lack of consent ought to be part of the offence think that what the second person has to answer for is uniquely, especially bad, even before any question of a defence is raised, and that it is correctly addressed by the crime of "rape". Consequently, recasting the offence of rape as sexual penetration alone cannot but challenge the normative importance of consent

57 Campbell, "Offence and Defence" pp. 80-81. 
to the distinct wrong that rape is. It is, effectively, to re-run the argument about whether lack of sexual consent is germane to the wrongness of rape.

Defenders of the alternative view would have plenty of cheerleaders on that mission, not the least from feminist critics unconvinced that the law's notion of 'consent' accurately marks out the most serious sexual misconduct. There is no space here to embark on a discussion about whether the absence of consent (with correlative mens rea) is intrinsic to the distinctive wrong that we ought to capture in "rape", cognisant that there are consensual sexual interactions which are nonetheless unwelcome, exploitative, and grim. The significance of consent to the wrongness of rape warrants a theory of its own. ${ }^{58}$ The main point, though, is that challengers of the orthodoxy cannot have it both ways with consent: they cannot agree that the overriding of consent is critical to the distinctive wrong that rape is, as compared with other kinds of sexual misconduct (as Wall, for one, seems to do in regarding consent as normatively 'transformative'), and yet hold that it could be excised from the presumptive wrong for which people are called upon to answer in the crime of rape.

Westen's claim, more specifically, is that the presumptive wrong of rape is only sometimes that of sexual intercourse as such (presumably in exploitative, unsettling contexts such as the example he gives); whereas at other times it is non-consensual sexual penetration. It is true, as we have noted, that whether or not there are any moral costs to sex does not hinge solely on consensuality. But the presumptive wrong of rape cannot be a moving target, as this claim by Westen suggests. Either lack of consent is an integral feature of this particular wrong or it isn't. There can of course be costs to sex which 'morally ought to be addressed', to use Westen's terms, that do not encapsulate the wrong of rape. Betrayal might be one of them. But sexual penetration does not turn into the presumptive wrong of rape by virtue of being treacherous. Westen's remarks here might be thought, then, only to demonstrate his scepticism that there are distinctive moral costs to rape (as opposed to other kinds of sexual misconduct) that ought to be addressed through a targeted criminal offence.

\section{Concluding Remarks}

Perhaps, in the end, Gardner's invitation to anyone who thinks sexual intercourse as such should be the actus reus of rape to find 'general reasons' against sex was a little too inviting. That is tempting bait to resist, especially when reasons are so easy to come by. The same could be said to go for the 'unwelcome turn of events per se' test. As Westen and Wall do rightly point out, we certainly cannot say that penetrative sex per se is welcome. Instead of turning on the idea of acting against

\footnotetext{
58 Scholarly explanations have invoked the importance of sexual freedom, both negative and positive, which, it has been argued, includes the freedom to 'go wrong' in the sexual domain, and allow others to 'go wrong' with you (Gardner and Shute, "Wrongness of Rape", p. 20). Consent and consent-astuteness, it is further argued, makes all the difference between treating a person partially as an instrument or a means of sexual gratification and treating her wholly or merely as such a means. The consent-astute person can still cynically use and objectify someone else in sex, but not to the same degree as the person who imposes sex on another regardless of her consent.
} 
reasons, though, we would, I think, better understand the crux of Gardner's account of the offence-defence distinction as turning on the notion of breaching a serious moral duty to fellow human beings, no matter whether defensibly or unavoidably. Elsewhere, he rejects the so-called 'closure view' according to which 'no action is wrong unless it is wrong all things considered' in favour of the view that justified wrongs persist in being wrongs in at least some way, capable of leaving 'a blemish on one's life' and hence leaving 'logical space for the classical idea of the tragic'. ${ }^{59}$ Applying this to rape liability, then, the suggestion is that subjecting another person to non-consensual sex breaches an especially serious moral duty-in respect of which one must be called to answer criminally - albeit there may be moral costs to address in many instances of consensual sex.

The orthodox view of offences and defences in rape is predicated on the view that the duty to avoid this particular conduct is especially solemn. Were we to grant Wall, Dempsey and Herring that all literal 'applications of force' are pro tanto moral wrongs in themselves, it is nonetheless clear that this form of pro tanto wronging cannot be assimilated with the wrong of rape. Whatever duty of avoidance attaches to applications of force qua applications of force is not comparable to the duty to avoid raping someone. Hence, one cannot make the leap from establishing that sexual penetration is the pro tanto wrong of applying force to another to holding that it ought to be the actus reus of rape.

I am in any event unconvinced that a general duty of avoidance does attach to all 'applications of force', even if they do implicate our bodily rights. Surgery, defined as necessary medical treatment, breaches no duty and is not wrong even pro tanto. Likewise, it is far from clear that rugby, massage, dancing the tango, and a host of other activities that involve interpersonal physicality, by virtue of that physicality alone, admit of general duties of avoidance. Needless to say, 'applications of force' is a strained description for many forms of interpersonal physicality, and this includes mutually engaged sexual intercourse. In categorising all such activities as pro tanto wrongdoing, the main mistake these theorists have made, I believe, is to equate conduct that would be wrongful but for the giving of consent (by one party or by more than one) with conduct that is always wrongful 'pro tanto'. Certainly, it would be wrong to force someone to play rugby, or to dance the tango. But it does not follow that this gives rise to a duty to avoid rugby or tango as such, or in 'all instances'.

Dempsey and Herring are correct that physical activities such as surgery or rugby have downsides. Rugby players develop cauliflower ear; surgery can be painful, risky, and requires recovery. But these are more properly thought of as purely rational remainders than moral remainders of the kind that characterise pro tanto wrong conduct. They are no more than reasons weighing against the activities, not the basis of a general duty to avoid them at all times. Moreover, it strikes me that even the rational remainders associated with things such as surgery or rugby are not a function of their being 'applications of force', though they result from physical contact. It counts against playing rugby that you might get hurt in a tackle, or

\footnotetext{
${ }^{59}$ See John Gardner, "In Defence of Defences", in Offences and Defences: Selected Essays in the Philosophy of Criminal Law (Oxford, OUP, 2007): pp. 77-89, p. 81.
} 
develop cauliflower ear, just as it counts against being a ballerina that your toes might end up bent out of shape. The weight of the rational remainders derives from the possible harmfulness of the activities, and it seems to matter no more that in rugby, but not in ballet, this will be the direct result of physical contact from others. It is, if anything, the harms of rugby, not the pure applications of force, which generate remainders.

I am sceptical, then, that all activities involving applications of force are pro tanto wrongs qua applications of force. But my main contention here has not been about the conditions of pro tanto wrongdoing. My interest has rather been whether the conceptual distinction between offences and defences on which the orthodox view of rape liability rests could ground a case for stripping back the actus reus of rape to sexual penetration alone. As I have tried to show, to argue that it can begs the question as to whether culpable non-consensual sexual penetration should ever have been marked out for special censure under the heading of "rape". Those that think the law is in error to identify the prohibited conduct of "rape" as sex without consent, and nothing else, might welcome this challenge. My argument has only been that critics of the orthodoxy cannot track a middle way between affirming the importance of consent for the central criminal wrong of rape, and arguing that reference to consent ought to be kept out of its offence-subset.

A final objection of the following sort might be raised. Perhaps, it might be argued, consent remains as central to the criminal wrong of rape if relocated into the defence-subset. It is no less a part of what defendants are called to answer for, it might be said, as long as proving consent is still exonerating. To be sure, for anyone who doubts there is a meaningful difference between offence elements and justificatory defences, this has all been so much profitless hand-wringing. But to argue thusly simply denies that conceptual distinction altogether, and with it any basis for recasting the offence-subset of rape as sexual penetration per se. It is part and parcel of thinking in terms of offences and defences in the strict sense that while both matter for criminal conviction, one captures the prohibited conduct in a special, closed sort of way. If that is not so, then there is no reason to worry about where consent should sit in the structure of rape liability, but neither is there a theoretical basis for marking out penetrative sex alone as the actus reus of rape.

Open Access This article is licensed under a Creative Commons Attribution 4.0 International License, which permits use, sharing, adaptation, distribution and reproduction in any medium or format, as long as you give appropriate credit to the original author(s) and the source, provide a link to the Creative Commons licence, and indicate if changes were made. The images or other third party material in this article are included in the article's Creative Commons licence, unless indicated otherwise in a credit line to the material. If material is not included in the article's Creative Commons licence and your intended use is not permitted by statutory regulation or exceeds the permitted use, you will need to obtain permission directly from the copyright holder. To view a copy of this licence, visit http://creativecommons.org/licen ses/by/4.0/.

Publisher's Note Springer Nature remains neutral with regard to jurisdictional claims in published maps and institutional affiliations. 